\title{
Penerapan Media E-Journal Menggunakan Sistem IJC berbasis OJS di STT YUPPENTEK
}

\section{Media E-Journal Application Uses the OJS-based IJC System at STT YUPPENTEK}

\author{
Indri Handayani ${ }^{1}$, Erick Febriyanto ${ }^{2}$, Yuliana $^{3}$ \\ Sekolah Tinggi Manajemen dan Ilmu Komputer (STMIK) Raharja \\ Jl. Jend. Sudirman No. 40, Modern Cikokol, Tangerang \\ 1indri@ raharja.info $, \underline{\text { erick@ } @ \text { raharja.info }}{ }^{2},{ }^{3}$ yuliana.yuli@ raharja.info
}

\begin{abstract}
Abstrak
Pada teknologi yang berkembang saat ini sudah mampu menyajikan informasi yang informatif dan sangat mudah untuk didapatkan berupa elektronik. Namun pada STT YUPPENTEK dalam pengelolaan jurnal atau karya ilmiah lainnya masih menggunakan cara konvensional atau manual sehingga menimbulkan beberapa permasalahan yaitu pada saat proses terbit jurnal membutuhkan waktu yang cukup lama, karena sudah terlalu lama data - data menjadi terpisah - pisah dan dari segi biayapun membutuhkan biaya yang cukup besar, dalam pengelolaan karya ilmiahnya pun belum memenuhi syarat yang ditentukan oleh dikti dengan perihal akreditas jurnal yang mengharuskan jurnal dikelola secara online karena dengan begitu akan lebih mudah dan cepat. Dengan adanya iJC (iLearning Journal Center) dapat mempublikasikan jurnal secara online, memudahkan pengguna untuk submit jurnal, mengubah pengelolaan $e$ journal menjadi lebih terdistribusi dan dapat mempermudah proses penyerahan naskah, review, edit, sampai dengan tahap publikasi serta dengan menggunakan iJC (iLearning Journal Center) akan menghasilkan e-journal yang berkualitas. Pada penelitian ini peneliti menggunakan beberapa metode yaitu metode observasi, wawancara, dan studi pustaka serta menggunakan UML (Unified Modeling Language).
\end{abstract}

Kata Kunci-e-journal, IJC, STT YUPPENTEK

\section{Abstract}

In developing technology, it is now able to present information that is informative and very easy to obtain in the form of electronics. But in STT YUPPENTEK in managing journals or other scientific works still using conventional or manual methods so that it raises several problems, namely when the journal publishing process takes a long time, because the data has been too long separated and in terms of cost requires which is quite large, the management of scientific work has not yet fulfilled the requirements determined by the dictation with regard to journal accreditation which requires the journal to be managed online because it will be easier and faster. With iJC (iLearning Journal Center) can publish journals online, making it easier for users to submit journals, change the management of e-journals to be more distributed and can simplify the process of submitting manuscripts, reviews, edits and publication using iJC (iLearning Journal Center) will produce quality e-journals. In this study researchers 
used several methods, namely the method of observation, interviews, and literature studies and using UML (Unified Modeling Language).

Keywords-E-journal, IJC, STT YUPPENTEK

\section{PENDAHULUAN}

Teknologi pada saat ini berkembang sangatlah pesat sehingga mampu menyajikan informasi yang informatif dan mudah untuk didapat dalam bentuk elektronik dengan begitu keinginan untuk memberikan pelayanan yang baik dan mempermudah pengguna untuk mengakses lebih cepat semakin besar.

STT YUPPENTEK adalah sebuah Perguruan Tinggi yang berada di kota Tangerang yang khusus untuk bidang teknik seperti teknik mesin, teknik listrik, teknik sistem komputer dan teknik industri yang dalam pengelolaan jurnalnya masih dengan konvensional atau masih secara manual oleh karena itu iJC (iLearning Journal Center) memiliki tujuan agar STT YUPPENTEK dapat mempublikasikan jurnal secara online.

Pada dasarnya untuk mempublikasikan suatu karya ilmiah dalam artikel ilmiah ataupun jurnal melibatkan banyak proses dan peran. Beberapa proses yang dibutuhkan hingga sebuah artikel ilmiah layak untuk diterbitkan atau dipublikasikan ke dalam jurnal ilmiah yaitu proses penyerahan naskah oleh penulis, seleksi awal, reviewer, pengiriman revisi (jika ada yang perlu diperbaiki), dan editoring sehingga artikel ilmiah dapat layak dipublikasikan dan di terbitkan ke dalam sebuah jurnal.

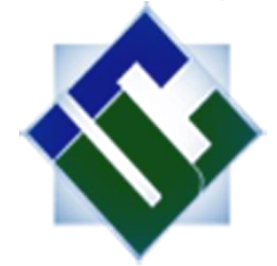

Gambar 1. Logi IJC (iLearning Journal Center)

Sumber : journal.ilearning.co

iLearning Journal Center (IJC) adalah sebuah inovasi sistem jurnal elektronik (e-journal) pada penerapannya dijadikan arahan untuk dapat menggantikan sistem pengelolaan jurnal konvensional (tercetak), iJC dengan menggunakan Open Journal System (OJS) dari PKP (Public Knowledge Project) sebagai dasarnya mampu memberikan kemudahan, kecepatan, serta integritas dalam melakukan pengelolaan jurnal.[1]

Pada saat ini banyak sekali teknologi yang baru dengan perkembangan yang sangat canggih, tanpa disadari saaat ini sudah sampai dengan karya ilmiah yang dapat di kelola secara online atau dapat disebut dengan $e$-journal. Dalam $e$-journal, semua pihak yang meliputi pengelola, penulis reviewer dan pembaca dapat dilakukan secara online atau dapat dikatakan bahwa sistem e-journal berfungsi dalam mengotomatiskan proses pengiriman artikel, editting, review dan lainnya agar dapat diproses dengan cepat dan efisien. Sehingga Format e-journal kini banyak diminati karena pegeseran pola dan kebiasaan membaca dokumen elektronik dan kemudahan serta kecepatan akses hasilhasil penelitian dan kajian ilmiah [2].

Kewajiban untuk menghasilkan suatu jurnal merupakan keternutan yang diciptakan untuk meningkatkan mutu dan kualitas pendidikan di indonesia. Perguruan tinggi . Lembaga pendidikan yang bergerak saat ini harus selalu mengedepankan inovatif serta kreatif, banyaknya aplikasi yang sudah dibuat pengelolaan jurnal secara online tidak kalah penting dari sistem dan aplikasi lainnya yang dibutuhkan perguruan 
tinggi karena dengan adanya pengelolaan secara online maka jurnal yang ingin dipublikasi tidak akan tercecer [3]. Bahkan sebagian perguruan tinggi lainnya yang sudah menggunakan format e-journal demi mempermudah penulis dalam melakukan karya ilmiah, dan demi melatih mahasiswanya untuk mengolah informasi maka dijadikan suatu syarat kelulusan dalam proses validasi jurnal bagi mahasiswa sehingga mahasiswa pun dapat lebih mudah mendapatkan suatu nilai pada Perguruan Tinggi, dan sehingga mahasiswa dapat lebih terlatih dalam mengelola dan menulis karya ilmiah guna memberikan informasi terupdate kepada masyarakat lainnya.[4]

Tujuan dari pembuatan jurnal yang dijadikan syarat untuk kelulusan adalah dapat menguasai knowledge sharing yang tertanam pada masing - masing mahasiswa karena memang ini juga merupakan hal yang penting dalam suatu organisasi melalui proses penyebaran pengetahuan yang dihasilkan atau dimiliki berupa informasi menjadi suatu informasi yang lebih memiliki nilai yang berharga untuk di kembangkan yang mampu melihat setiap asset itu berharga dan mempunyai daya saing untuk setiap proses yang terjadi.[5].

Tetapi Banyak juga yang perguruan tinggi yang masih menggunakan sistem masih manual sehingga memiliki permasalahan-permasalahan seperti penerbitan jurnal yang begitu susah dan data terpisah-pisah karena membutuhkan waktu cukup lama dan biaya cukup besar Artikel ilmiah pada STISIP YUPPENTEK belum memenuhi syarat ketentuan dikti perihal akreditasi jurnal yang mengharuskan jurnal dikelola dengan cara online dalam pengelolaan yang dilakukan lebih dengan mudah dan cepat. Setelah peneliti menganalisa permasalahan dengan menggunakan suatu metode pengumpulan data berupa observasi, wawancara dan studi pustaka serta menggunakan UML (Unified Modeling Language). Untuk mengatasi permasalahan tersebut peneliti memberikan usulan sistem yang memudahkan pengguna sehingga proses pengelolaan jurnal dapat lebih memudahkan pengguna [6].

\section{METODE PENELITIAN}

Didalam sebuah penelitian pasti membutuhkan metode penelitian agar dapat lebih mudah memperoleh informasi yang akurat. Pada penelitian ini menggunakan beberapa metode penelitian diantaranya yaitu metode perancangan dan metode pengumpulan data yang dimana terdapat observasi, wawancara dan juga studi pustaka. Dan berikut merupakan gambar alur proses pengumpulan data :

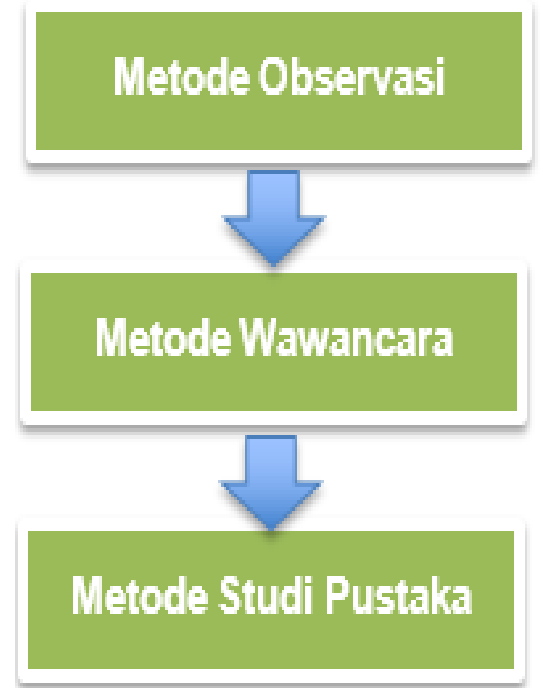

Gambar 2. Metode Penelitian 
Keterangan :

a. Metode Observasi

Adalah metode pengumpulan data yang dilakukan secara langsung dilokasi penelitian. Penelitian ini dilakukan pada STT YUPPENTEK guna memperoleh data yang akurat sesuai dengan yang terjadi

b. Metode Wawancara

Adalah metode yang digunakan oleh peneliti untuk mendapatkan informasi dengan cara melakukan tanya jawab pada pihak yang bersangkutan.

c. Metode Studi Pustaka

Adalah metode yang berguna untuk mendapatkan referensi peneliti dalam mendapatkan informasi yang akurat dari peneltian yang sebelumnya dilakukan dan metode penelitian ini berguna menyimpan informasi yang relevan dengan topik atau masalah yang relevan dengan topik yang ingin di teliti.

\section{HASIL DAN PEMBAHASAN}

Jurnal ilmiah adalah majalah publikasi yang memuat KTI (Karya Tulis Ilmiah) yang secara nyata mengandung data dan informasi yang mengajukan iptek dan ditulis sesuai dengan kaidah - kaidah penulisan ilmiah serta diterbitkan secara berkala. Pada dasarnya, ada 2 macam jurnal yaitu jurnal konvensional (cetak) dan jurnal elektronik (non cetak).[7]

Open Journal System (OJS) merupakan solusi sumber terbuka untuk mengatur, membantu dan menerbitkan jurnal ilmiah secara on-line[8]. Open Journal System (OJS) merupakan sistem pengaturan dan penerbitan jurnal dengan tingkat pengoperasian yang sangat mudah dan dapat didownload secara gratis dan diinstal ke penyedia web lokal. Open Journal System (OJS) telah dirancang untuk mengurangi waktu dan tenaga yang disediakan untuk tugas-tugas penulisan dan pengelolaan yang berhubungan dengan mengedit sebuah jurnal sementara meningkatkan record-keeping dan efisiensi proses pengeditan. Open Journal System (OJS) dimaksudkan untuk meningkatkan kualitas keilmiahan dan kualitas umum dalam penerbitan jurnal melalui sejumlah inovasi, dimulai dari pembuatan polis jurnal yang lebih transparan untuk meningkatkan indeks.[8]

Namun perkembangan teknologi dan informasi saat ini mampu menjadikan jurnal memiliki beragam macamnya dan juga menjadi alasan perguruan tinggi diharuskan memberikan fasilitas sebuah pencarian informasi secara lebih cepat, lebih efisien, lebih efektif, dan hemat biaya.

iLearning Jurnal Center (iJC) merupakan sistem yang mempermudah pengelolaan dan penerbitan jurnal secara online atau biasa disebut dengan e-journal, sistem ini menggunakan Open Journal System (OJS) yang dikembangkan oleh PKP (Public Knowledge Project) secara Open Source dengan artian dapat dikembangkan oleh siapa saja. iJC (iLearning Journal Center) memiliki tujuan yaitu STT YUPPENTEK dapat mempublikasikan jurnal secara online.

Pengelolaan data jurnal yang diterapkan di STT Yupentek masih menggunakan sistem jurnal konvensial sehingga hal ini menimbulkan beberapa permasalahan yaitu kurang efektif dan efisien, dah proses penyerahan naskah juga cukup rumit karena mengharuskan datang ke STT YUPPENTEK. 


\section{Use Case Diagram yang diusulkan}

Didalam Gambar 3 terdiri dari 3 actor yaitu editor jurnal, reviewer jurnal dan author Jurnal, digunakan Use Case Glossary dan Actor Glossary yaitu untuk menjelaskan deskripsi secara singkat dan menjelaskan prosedur sistem yang diusulkan.

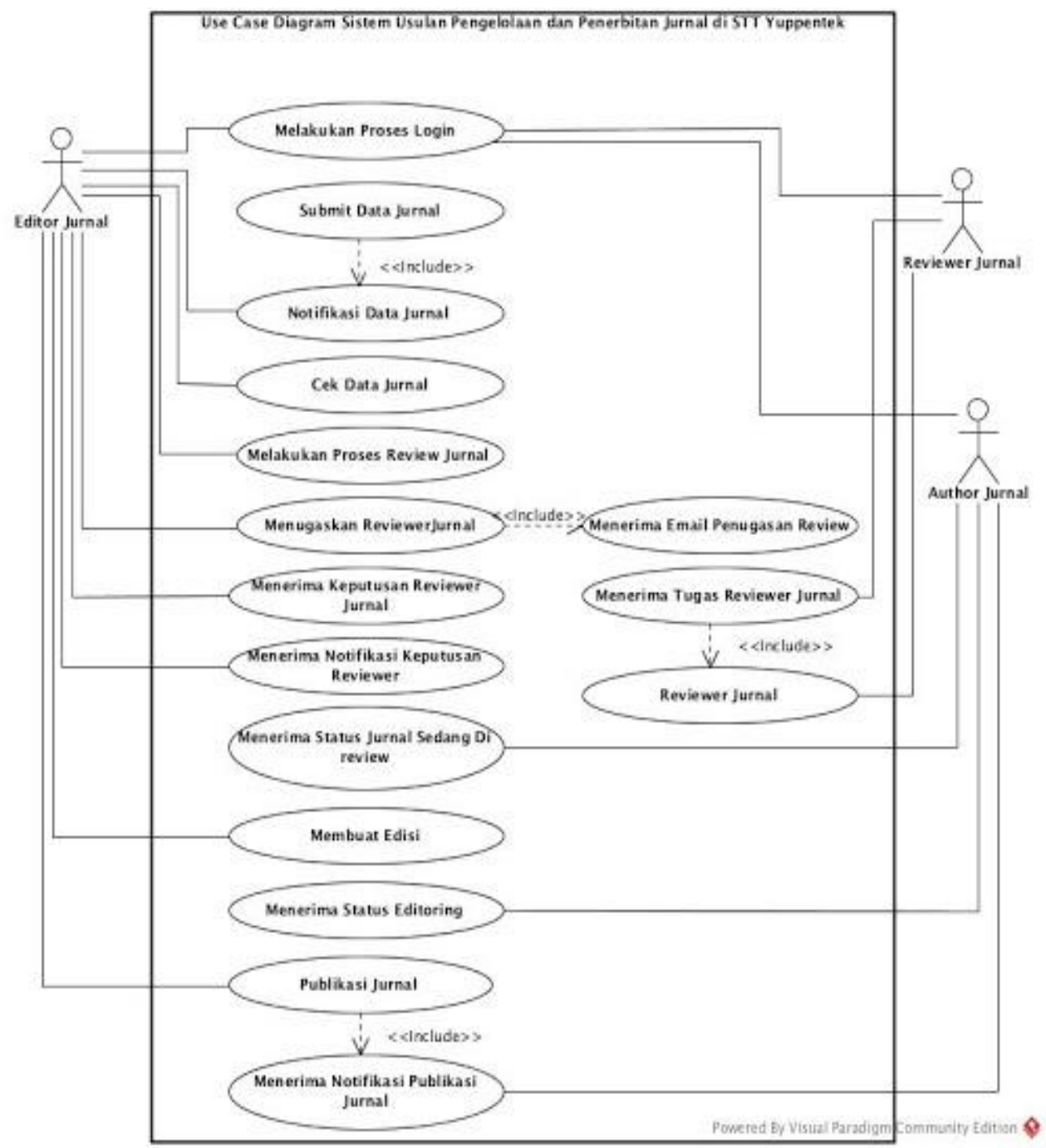

Gambar 3. Use Case Diagram Usulan

\section{Actor Glossary}

Dibawah ini adalah tabel yang menjelaskan secara singkat dari 3 actor yang telah ditentukan oleh Use Case Diagram yang diusulkan.

Tabel.1 Actor Glossary

\begin{tabular}{cll}
\hline No. & \multicolumn{1}{c}{ Aktor } & \multicolumn{1}{c}{ Deskripsi } \\
\hline 1. & Editor Jurnal & $\begin{array}{l}\text { User yang memiliki hak access untuk mengelola data } \\
\text { jurnal secara keseluruhan }\end{array}$ \\
\hline 2. & Review Jurnal & $\begin{array}{l}\text { User yang memiliki hak access untuk mereview jurnal } \\
\text { yang tersedia }\end{array}$ \\
\hline 3. & Author Jurnal & $\begin{array}{l}\text { User yang memiliki hak } \text { access untuk membuat data jurnal } \\
\text { dan submit data jurnal }\end{array}$ \\
\hline
\end{tabular}




\section{Use Case Glossary}

Berikut adalah tabel menjelaskan secara singkat yang terdiri dari 3 actor yang telah ditentukan dengan use case yang saling berhubungan.

Tabel.2 Use Case Glossary

\begin{tabular}{|c|c|c|}
\hline No. & Use Case & Deskripsi \\
\hline 1. & Melakukan Proses Login & $\begin{array}{l}\text { User yang akan mengelola data jurnal harus melalui } \\
\text { proses login yaitu dengan memasukkan username dan } \\
\text { password }\end{array}$ \\
\hline 2. & Submit data Jurnal & $\begin{array}{l}\text { User yang akan jurnalnya dipublikasi harus } \\
\text { melakukan proses submit data jurnal }\end{array}$ \\
\hline 3. & Notifikasi data jurnal & $\begin{array}{l}\text { Mamberikan informasi data jurnal kepada pihak } \\
\text { editor jurnal, apabila ada jurnal yang baru saja di } \\
\text { submit }\end{array}$ \\
\hline 4. & Cek data jurnal & Editor melakukan pengecekkan data jurnal. \\
\hline 5. & $\begin{array}{l}\text { Melakukan Proses } \\
\text { Review Jurnal }\end{array}$ & $\begin{array}{l}\text { Editor melakukan review jurnal sebelum diberikan } \\
\text { kepada reviewer }\end{array}$ \\
\hline 6. & $\begin{array}{l}\text { Menugaskan Reviewer } \\
\text { Jurnal }\end{array}$ & $\begin{array}{l}\text { Editor memilih salah satu reviewer jurnal untuk } \\
\text { melakukan review jurnal }\end{array}$ \\
\hline 7. & $\begin{array}{l}\text { Menerima email } \\
\text { penugasan }\end{array}$ & $\begin{array}{l}\text { Reviewer yang telah dipilih akan mendapatkan email } \\
\text { penugasan. }\end{array}$ \\
\hline 8. & $\begin{array}{l}\text { Menerima tugas review } \\
\text { jurnal }\end{array}$ & $\begin{array}{l}\text { Reviewer menerima tugas review yang telah diberikan } \\
\text { editor. }\end{array}$ \\
\hline 9. & Review Jurnal & Reviewer melakukan proses review jurnak \\
\hline 10. & $\begin{array}{l}\text { Menerima Keputusan } \\
\text { reviewer jurnal }\end{array}$ & $\begin{array}{l}\text { Reviewer akan memberikan hasil review jurnal } \\
\text { kepada editor. }\end{array}$ \\
\hline 11. & $\begin{array}{l}\text { Menerima Keputusan } \\
\text { Review Jurnal }\end{array}$ & $\begin{array}{l}\text { Editor akan menerima hasil keputusan jurnal dari } \\
\text { reviewer jurnal dengan status ditolak / direvisi }\end{array}$ \\
\hline 12. & $\begin{array}{l}\text { Menerima notifikasi } \\
\text { keputusan reviewer }\end{array}$ & $\begin{array}{l}\text { Informasi mengenai keputusan review terhadap jurnal } \\
\text { akan diterima oleh editor }\end{array}$ \\
\hline 13. & $\begin{array}{l}\text { Menerima status jurnal } \\
\text { sedang di review }\end{array}$ & $\begin{array}{l}\text { Status jurnal yang telah direview oleh reviewer akan } \\
\text { di terima oleh author jurnal. }\end{array}$ \\
\hline & Membuat Edisi & $\begin{array}{l}\text { Edisi jurnal yang telah lulus review akan di buatkan } \\
\text { oleh editor }\end{array}$ \\
\hline 15. & $\begin{array}{l}\text { Menerima status } \\
\text { editoring }\end{array}$ & $\begin{array}{l}\text { Status editoring jurnal akan diterima oleh author } \\
\text { jurnal }\end{array}$ \\
\hline 16. & Publikasi Jurnal & $\begin{array}{l}\text { Editor jurnal akan melakukan proses publikasi } \\
\text { terhadap jurnal yang telah lulus review dan telah } \\
\text { melakukan proses edisi jurnal }\end{array}$ \\
\hline & $\begin{array}{l}\text { Menerima notifikasi } \\
\text { publikasi jurnal }\end{array}$ & $\begin{array}{l}\text { Pesan notifikasi terhadap publikasi jurnal akan } \\
\text { diterima oleh author jurnal }\end{array}$ \\
\hline
\end{tabular}

\section{Implementasi Sistem}

1. Tampilan Home 
Berantauc Terkini Arsip Pengumuman Tentangkami *
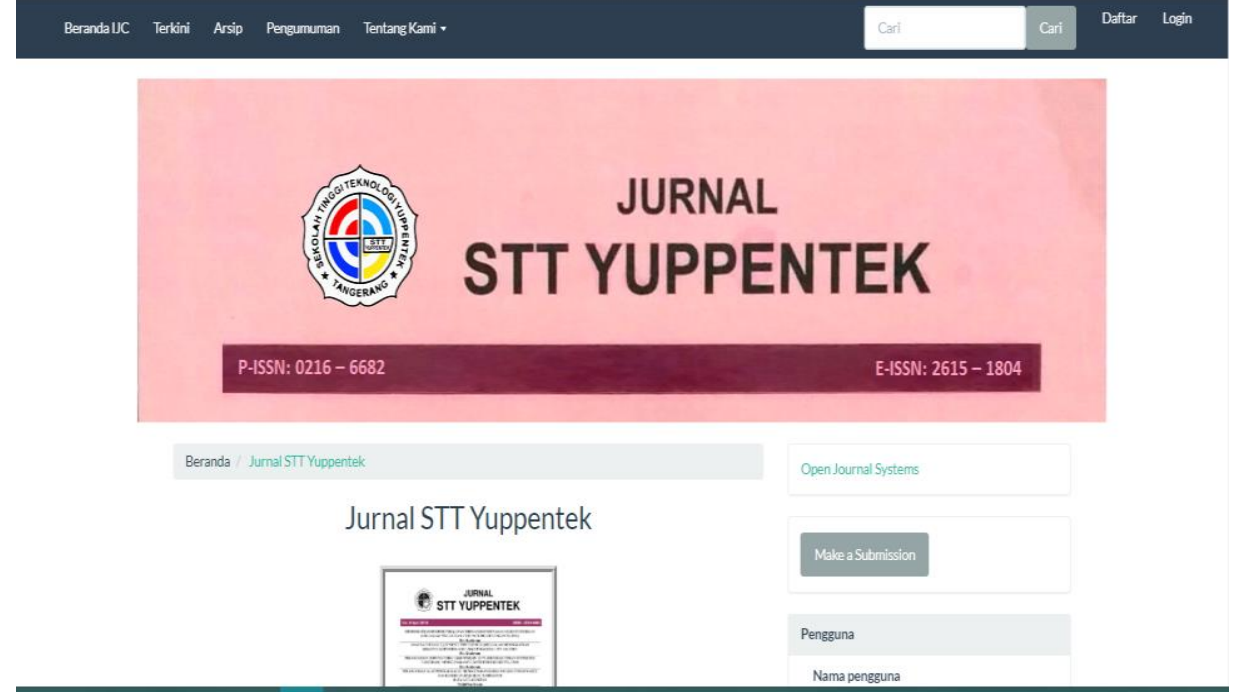

Gambar 4. Tampilan Home

(Sumber : http://ijc.ilearning.co/index.php/sttyuppentek )

Tampilan pada halaman home adalah halaman yang tersedia pada saat mengunjungi website tersebut atau dapat dikatakan halaman yang pertama kali dilihat klien/pengunjung saat mengakses website. Tujuannya adalah untuk membuat pengunjung tertarik menjelajah website lebih jauh lagi. Pada tampilan home juga pengunjung dapat mengetahui informasi artikel yang sudah di terbitkan oleh pihak jurnal STT Yuppentek

\section{Form Login}
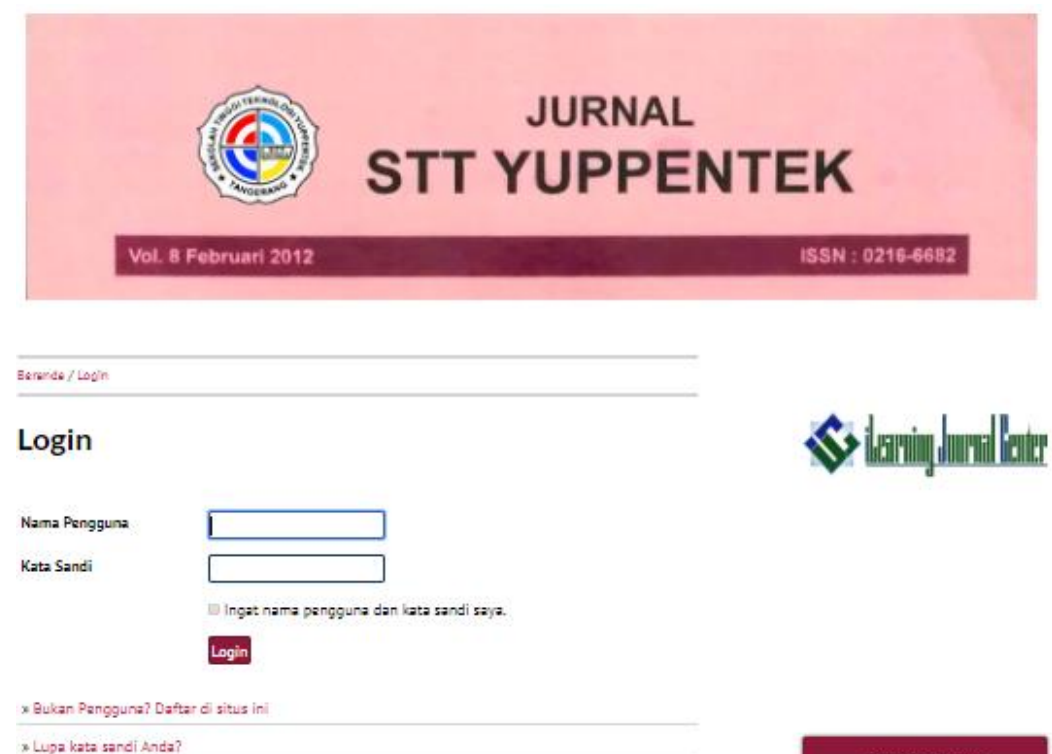

Gambar 5. Form Login

(Sumber: http://journal.ilearning.co/index.php/sttyuppentek/login )

Form login adalah tampilan yang menyediakan field nama pengguna dan kata sandi seperti tampilan login pada umumnya disertai dengan petunjuk jika pengguna ingin membuat akun atau lupa password. Pada form login ini pengunjung yang telah 
memiliki akun dapat langsung masukkan nama pengguna dan juga kata sandi tetapi untuk yang belum mempunyai akun maka cobalah untuk klik menu register yang sudah disediakan.

\section{Tampilan Menu Daftar}

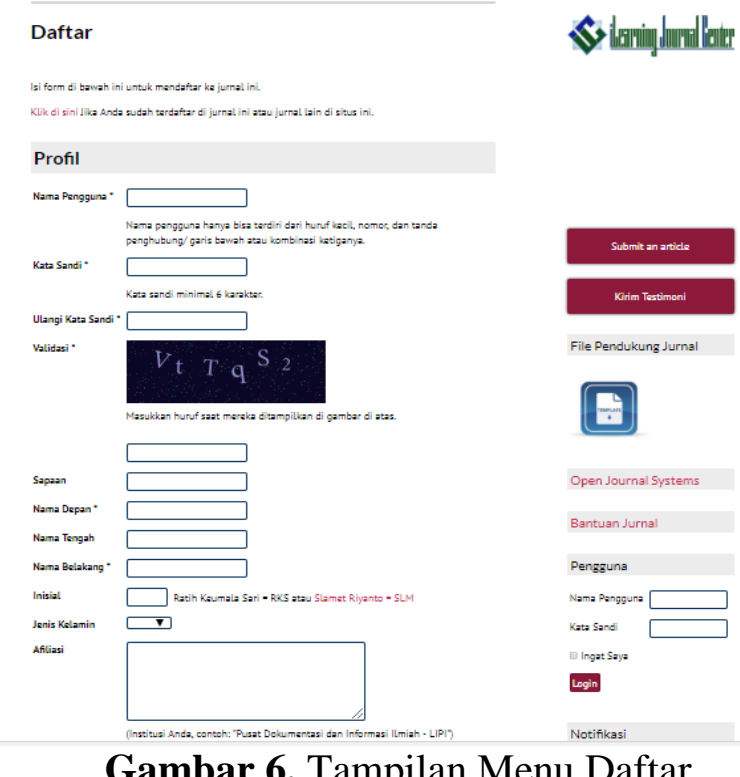

(Sumber : http://journal.ilearning.co/index.php/sttyuppentek/user/register)

Menu daftar berfungsi untuk pengguna yang belum memiliki akun, didalamnya pengguna diharuskan mengisi form yang sudah di sediakan dengan lengkap sesuai dengan instruksi, sehingga dapat mempermudah penulis untuk mensubmit hasil karya yang telah di buatnya

\section{Tampilan Menu Tentang Kami}
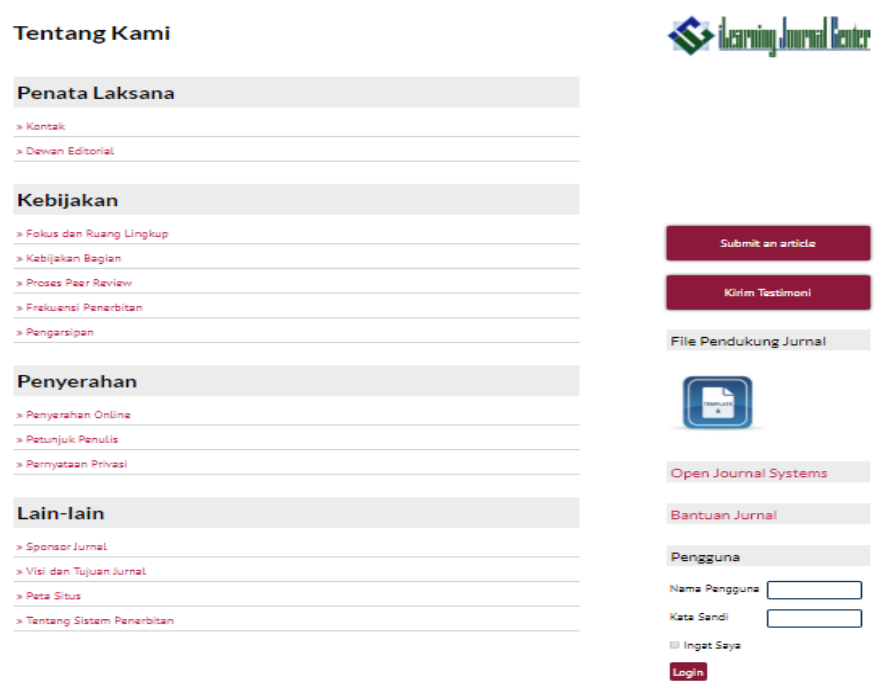

Gambar 7. Tampilan Menu Tentang Kami

(Sumber : http://journal.ilearning.co/index.php/sttyuppentek/user/register) 
Menu tentang kami dapat di akses di tampilan halaman awal dimana berisi hal seputar jurnal mulai dari pelaksanaan, kebijakan, penyerahan jurnal dan hal lain yang berhubungan, sehingga pengunjung dapat lebih mengenal jurnal yang diterapkan di STT Yuppentek dan pada halaman ini juga tersedia menu kontak yang dimana artinya pengunjung tidak kesulitan untuk mendapatkan informasi mengenai pihak jurnal yang ingin di hubungi.

\section{Tampilan Beranda Pengguna}

Berenda/Beranda Pungguna

Beranda Pengguna

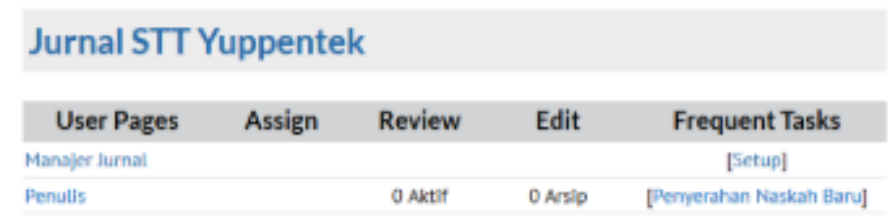

\section{Akun Saya}

, lunjubaan Jurnal Saya

s Eall Protil Saya

Gambar 8. Tampilan Beranda Pengguna

(Sumber : http://ijc.ilearning.co/index.php/sttyuppentek/user)

Beranda pengguna ini menampilkan peran mulai dari manajer jurnal, editor, editor bagian author dan reviewer serta hak akses yang ditampilkan berbeda sesuai dengan perannya, pada halaman ini juga hanya bisa di akses oleh pengguna yang sudah login.

\section{KESIMPULAN}

Berdasarkan penelitian diatas membahas pengelolaan dan penerbitan jurnal pada STT YUPPENTEK masih dengan konvensional atau masih secara manual oleh karena itu iJC (iLearning Journal Center) memiliki tujuan agar STT YUPPENTEK dapat mempublikasikan jurnal secara online maka kesimpulan dari penelitian diatas adalah dengan adanya sistem $e$-journal ini memudahkan pengguna untuk submit jurnal, dengan menggunakan iJC dapat mengubah pengelolaan e-journal menjadi lebih terdistribusi dan dapat mempermudah proses penyerahan naskah, review, edit, sampai dengan tahap publikasi serta dengan menggunakan iJC (iLearning Journal Center) akan menghasilkan e-journal yang berkualitas.

\section{SARAN}

Media $e$-journal menggunakan sistem IJC pada STT YUPPENTEK adalah salah satu cara untuk memudahkan pengguna dalam submit jurnal secara online. Namun pengembangan selanjutnya diharapakan dapat menjadi lebih baik lagi dari segi tampilan hingga submit jurnal pada STT YUPPENTEK. 


\section{UCAPAN TERIMAKASIH}

Peneliti mengucapkan terimakasih kepada para pihak yang terkait dan membantu dalam proses penyelesaian penelitian ini. Terutama peneliti mengucapkan terimakasih kepada Tuhan Yang Maha Esa, karena atas karunia dan nikmat-Nya penelitian ini dapat terselesaikan dengan baik. Lalu, yang kedua peneliti mengucapkan terimakasih kepada penulis 1 dan penulis 2 karena telah memberikan waktu dan bimbingannya selama penelitian ini berlangsung. Kemudian yang ketiga terimakasih kepada STMIK Raharja yang telah memfasilitasi tempat selama penelitian ini berlangsung, dan yang terakhir terimakasih kepada semua team IJC yang telah membantu dalam memberikan motivasi dan arahan.

\section{DAFTAR PUSTAKA}

[1] Handayani, I.(2015). Pemanfaatan Sistem Ime (Ilearning Media) Dan Rinfo (Raharja. Info) Dalam Penerapan Sistem E-journal Di Ccit Journal Pada Perguruan Tinggi Raharja.

[2] Handayani, I., Aini, Q., \& Oktaviani, F. (2016). Penerapan Sistem Validasi Jurnal Di Pessta+ Sebagai Penilaian Artikel Ilmiah Dalam Mendukung Kegiatan Civitas Akademika. Csrid (Computer Science Research And Its Development Journal), 8(3), 177-190.

[3] Aripianti, P., \& Widuri, R. (2016). Perancangan Sistem Informsi E-jurnal Pada Perguruan Tinggi Berbasis Web. Cerita Journal, 2(2), 189-198.

[4] Suroyo, S., \& Tanaamah, A. R. (2017). Peran E-journal Dalam Knowledge Sharing Sebagai Basis Pengelolaan Pengetahuan Di Universitas Kristen Satya Wacana. Smatika Jurnal, 6(02), 05-12.

[5] Pamungkas, K. T., \& Susilo, A. (2018). Implementasi Aplikasi E-Journal Pada Lembaga Penelitian dan Pengabdian kepada Masyarakat (LPPM) Universitas Respati Indonesia.

[6] N. Fajrin, L. Kamelia, and T. Juhana, "Instalasi dan Implementasi Open Journal System di Local Area Network Laboratorium Telematika STEI-ITB", Prosiding - Seminar Nasional Teknik Elektro UIN Sunan Gunung Djati Bandung, pp. 18-29, Jan. 2018

[7] Handayani, I., Warsito, A. B., \& Pangestu, S. A. (2017). Pemanfaatan Website Raharja. Ac. Id Sebagai Media Informasi Dan Upload Artikel Untuk Ns-ccit Menggunakan Framework Yii. Ccit Journal, 10(1), 127-138.

[8] Wijaya, N. H. (2017). Pengembangan E-journal Hasil Penelitian Mahasiswa Fakultas Ilmu Kesehatan Universitas Respati Yogyakarta. Jurnal Teknologi Informasi Respati, 9(26). 